\title{
Zinc layer anode applied on reinforced concrete structures
}

\author{
Xavier Hallopeau ${ }^{1}$, Eugène Moucadeau ${ }^{1}$, Roberto Giorgini ${ }^{2}$, Olivier Lesieutre ${ }^{1}$, Arnaud Meillier ${ }^{l}$, Camille \\ Annede-Villeau ${ }^{1}$ \\ ${ }^{1}$ Freyssinet International \& Cie, Technical Department, 92506 Rueil Malmaison Cedex, France \\ ${ }^{2}$ Corrpre, P.O.Box 387, 2740 AJ Waddinxveen, Netherlands
}

\begin{abstract}
The application of zinc layer anode to reinforced concrete structure has been well known for many years. This galvanic cathodic protection system was specified being a corrosion control system for general steel in concrete as well as civil structures. A good way to determine the dimensioning elements of the galvanic protection system, is to carry out a pilot test being monitored in situ, and exposed under on site conditions including local concrete remediation or repair works. This paper presents an analysis of the current distribution and steel polarization data that have been collected from a car park project in the French Alps.
\end{abstract}

\section{Introduction}

\subsection{Purpose}

The structure investigated was a car park in a ski resort in the Alps (France). This car park, built in 1979, covers 9 half-levels with a capacity of around 460 cars.

The structure is made entirely of reinforced concrete with a classical framework: columns, beams and slabs. The slabs are made with prefabricated slabs. The beams were pre-fabricated and keyed at the head of the columns.

\subsection{Project}

The corrosion survey, visual inspection with corrosion potential mapping and chloride content analysis following sample coring, revealed that the soffit of the slabs and the beams showed localized zones of corrosion depending on the parking levels.

Rebar corrosion can be triggered by a poor surface applied waterproofing coating, followed by chloride ingress due to de-icing salts, water build-up and cracks as shown in Figure 1, due to significant mechanical stress of concrete elements.

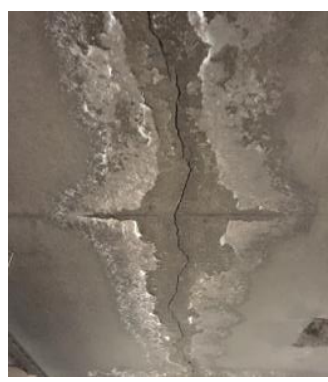

Fig. 1. Crack on soffit of slab
The car park rehabilitation project involves:

- Remediation of the surface applied sealing system preventing moisture and chlorides penetrating the concrete slab,

- Additional reinforcement avoiding concrete beam deflection,

- Installation of a galvanic cathodic protection system for corrosion control of steel in concrete.

\section{Cathodic protection system}

\subsection{Test area}

Cathodic protection zones considered for the pilot tests were as follows:

- Beam area: protection of all the rebars of the $6.5 \mathrm{~m}$ beam and the first $20 \mathrm{~cm}$ of reinforcement within the slabs adjacent to the beam, as shown in Figure 2.

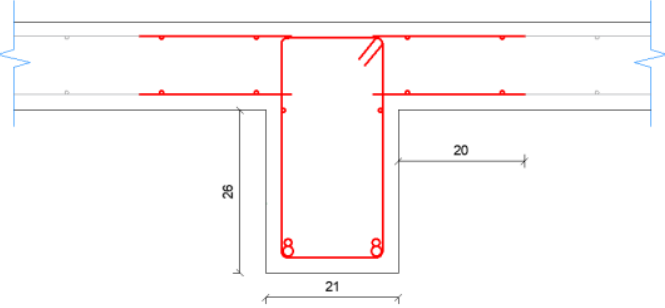

Fig. 2. Beam description

- Protection of the crack-oriented steel within the slab or deck as shown in Figure 3.

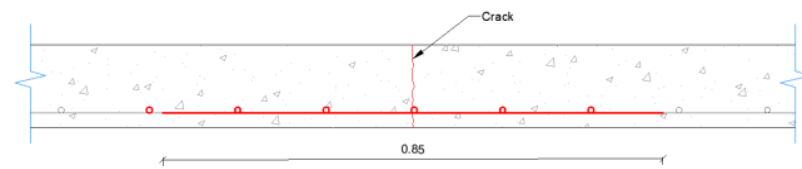

Fig. 3. Slab description

* Corresponding author: xavier.hallopeau @ freyssinet.com 


\subsection{Selection of the anodes}

The cathodic protection system defined for these pilot tests was a galvanic system (SACP) using $450 \mu \mathrm{m}$ zinc sheets $\left(3150 \mathrm{~g}\right.$ zinc $\left./ \mathrm{m}^{2}\right)$ called a Zinc Layer Anode (ZLA) $[1,2]$.

These anode strips are stuck on the concrete surface thanks to an ion-conductive adhesive.

\subsection{Application of the SACP pilot tests}

Prior to application, the concrete surface was prepared by grit blasting.

The electric steel continuity shown in Figure 4 (longitudinal reinforcement, stirrup, top bars, bottom bars), was checked for a resistance of less than $1 \mathrm{ohm}$ according to EN ISO 12696 [3]. In some cases, steel bars were welded to the existing reinforcement to restore electrical continuity.

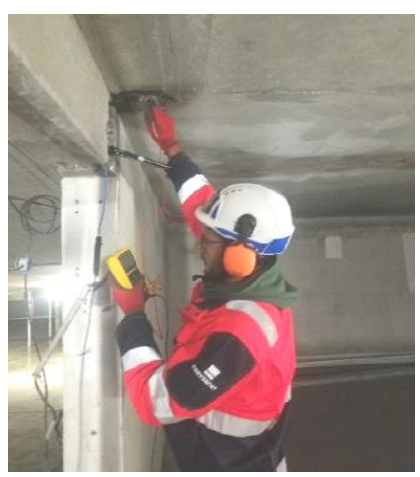

Fig. 4. Rebar electrical continuity test

In each $\mathrm{CP}$ zone, $5 \mathrm{~m}^{2}$ of concrete area, one ERE-20 electrode $\left(\mathrm{Mn} / \mathrm{MnO}_{2}\right)$ and five Titanium/MMO (MixedMetal-Oxide) potential decay probes were embedded in the concrete to monitor the throwing power and performance of the CP system at different locations.

Each electrode was placed in a borehole at a distance of 1 to $4 \mathrm{~cm}$ from a steel bar. Each electrode was connected to copper cable type XLPE/XLPE $2.5 \mathrm{~mm}^{2}$ blue color for reference electrodes and yellow for potential decay probes.

On the beams, one strip of ZLA $450 \mu \mathrm{m}$ was applied on each vertical side as shown in Figure 5 and 7.

On the crack area, one strip of ZLA $450 \mu \mathrm{m}$ was applied on both sides of the crack shown in Figure 6 and 8.
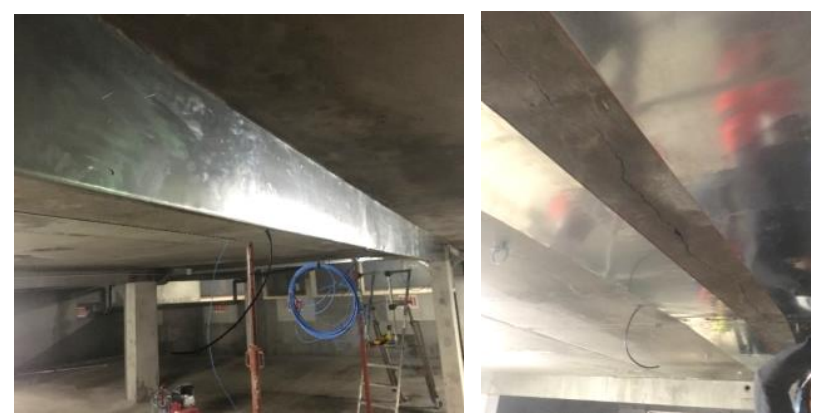

Fig. 5. ZLA on beam
Fig. 6. ZLA on slab soffit

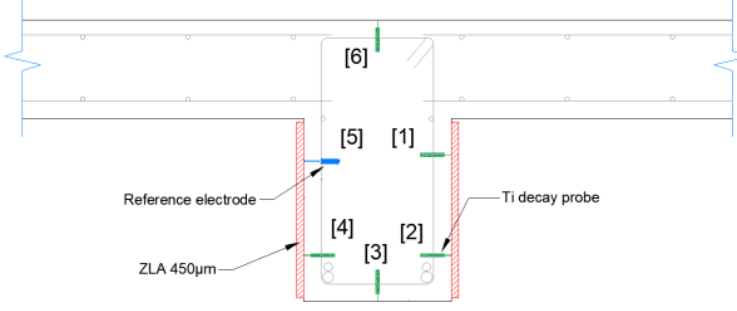

Fig. 7. Anode and monitoring description on beam

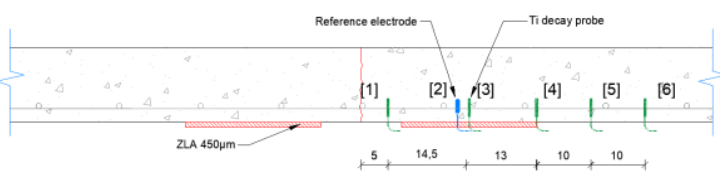

Fig. 8. Anode and monitoring description on slab soffit

The electrical continuity of the zinc layer at the overlaps was provided by plastic nails. The continuity was checked. For the connection of the anodes to the datalogger box, positive connections were made on site and were installed on the zinc sheet surface by using plastic nails. Each positive connection was connected to red copper cable type XLPE/XLPE $2.5 \mathrm{~mm}^{2}$.

All pilot test components were connected to copper XLPE/XLPE $2.5 \mathrm{~mm}^{2}$ cables, which are also connected to a voltage logger in the monitoring cabinet, shown in Figure 9.

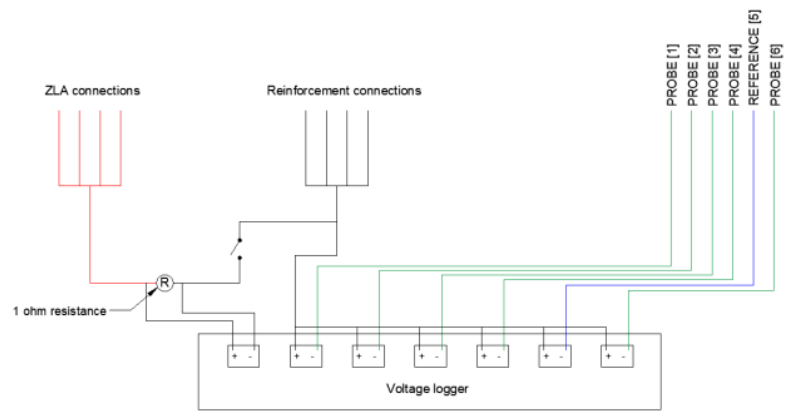

Fig. 9. Electrical scheme

Each test area was equipped with a data logger operating during the whole test period. The cables: anodic, cathodic and reference electrodes and potential decay probes, were all connected to this box. Each box was equipped with:

- Individual zinc strip to steel connections.

- Programmable data logger capturing and logging potentials and currents

- Temperature recorder.

\subsection{Data recording}

The data being measured included:

- Natural potential

- Polarization time

- Current per zone

- Potential ON

- Potential OFF at 0.5 to 1 second 


\section{- Depolarization \\ - Temperature}

In addition to the above-mentioned data being collected, potential mapping of the concrete surface adjacent to the zinc strips was performed using a $\mathrm{Ag} / \mathrm{AgCl}, \mathrm{KCl} 0.5 \mathrm{M}$ reference electrode.

\section{Results obtained on the beam area}

\subsection{Polarization effect on beam}

The following Table 1 shows the potential decay results after 21 days of the electrodes placed in the beam and the slab adjacent to the beam.

\begin{tabular}{|c|c|c|c|c|c|c|}
\hline Measures & $\begin{array}{c}E_{\text {native }} \\
12 / 06 / 2018\end{array}$ & $\begin{array}{c}E_{\mathrm{ON}} \\
12 / 06 / 2018\end{array}$ & $\begin{array}{c}E_{0 N} \\
02 / 07 / 2018\end{array}$ & $\begin{array}{c}E_{\text {instant-OFF }} \\
02 / 07 / 2018\end{array}$ & $\begin{array}{l}E_{0 F F}+24 h \\
03 / 07 / 2018\end{array}$ & 24h Decay \\
\hline $\begin{array}{c}\text { [1] - Dprobe } \\
(\mathrm{mV})\end{array}$ & -370 & -427 & -554 & -529 & -388 & 141 \\
\hline $\begin{array}{c}\text { [2] - Dprobe } \\
(\mathrm{mV})\end{array}$ & -387 & -467 & -603 & -566 & -414 & 153 \\
\hline $\begin{array}{c}\text { [3] - Dprobe } \\
\text { (mV) }\end{array}$ & -175 & -186 & -418 & -400 & -241 & 159 \\
\hline $\begin{array}{c}\text { [4] - Dprobe } \\
(\mathrm{mV})\end{array}$ & -221 & -235 & -456 & -406 & -211 & 195 \\
\hline $\begin{array}{c}\text { [5]-Ref } \\
(\mathrm{mV})\end{array}$ & -626 & -688 & -889 & -848 & -670 & 178 \\
\hline $\begin{array}{c}\text { [6] - Dprobe } \\
(\mathrm{mV})\end{array}$ & -265 & -280 & -397 & -390 & -247 & 143 \\
\hline $\begin{array}{l}\text { Current zone } \\
(\mathrm{mA})\end{array}$ & 0 & 269 & 136 & 0 & 0 & \\
\hline
\end{tabular}

Table 1. Potential shift, current and depolarization decay at 24 hours for one zone (beam)

The results show a significant effect of cathodic protection of the beam reinforcement:

- the instant-off to $24 \mathrm{~h}$ potential decay values,

- and the initial IR-drop when switching off the CP system.

The potential decay measured with the electrodes and probes makes it possible to validate the performance of the EN ISO 12696 standard, criteria b, i.e. a depolarization decay greater than $100 \mathrm{mV}$ over up to 24 hours after the system shutdown. It indicated sufficient corrosion control by the galvanic CP system.

These results validate the layout of the surface applied anode on the test beam and confirm the ability of the CP system to give sufficient corrosion control of the steel bars in the top of the beam (probe no. 6).

\subsection{Effect of beam polarization on closest slab soffit}

Potential mapping was performed on the surface of the soffit adjacent to the beam to evaluate the performance of the system shown in Figure 10.

The area mapping details were:

- Support: soffit slab adjacent to the beam

- Zone of mapping: $1.00 \mathrm{~m} \times 0.40 \mathrm{~m}$

- Grid of the mapping according to the direction of the beam: Axis-Y: $5 \mathrm{~cm}$, Axis-X: $10 \mathrm{~cm}$., 86 measurements - Electrode used: $\mathrm{Cu} / \mathrm{CuSO}_{4}$

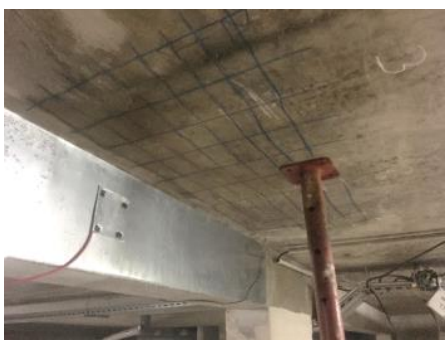

Fig. 10. Potential mapping area

Table 2 shows the mapped potentials of the CP-system being on after 21 days polarization and Table 3 shows the off potential values of the soffit surface area after 24 hours depolarization.

Table 2. Polarization effect $(\mathrm{ON})$

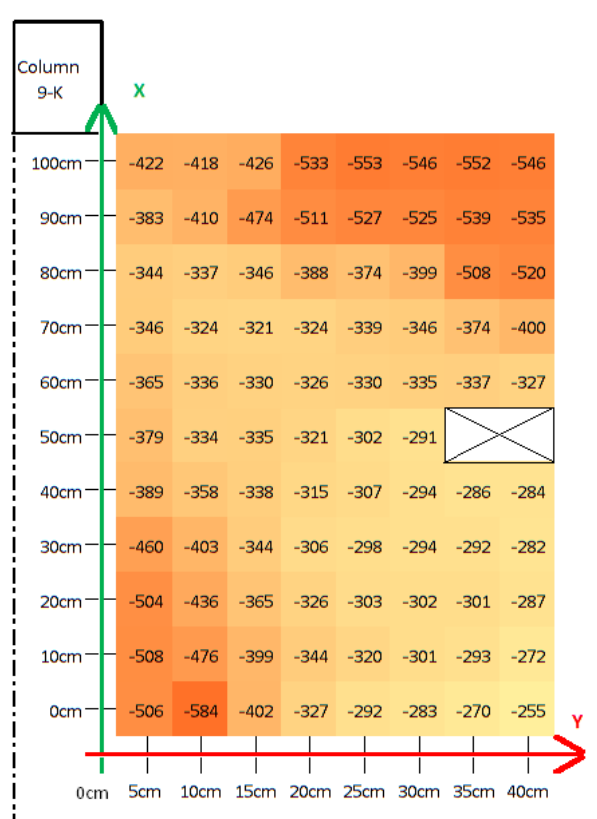

Table 3. Depolarization

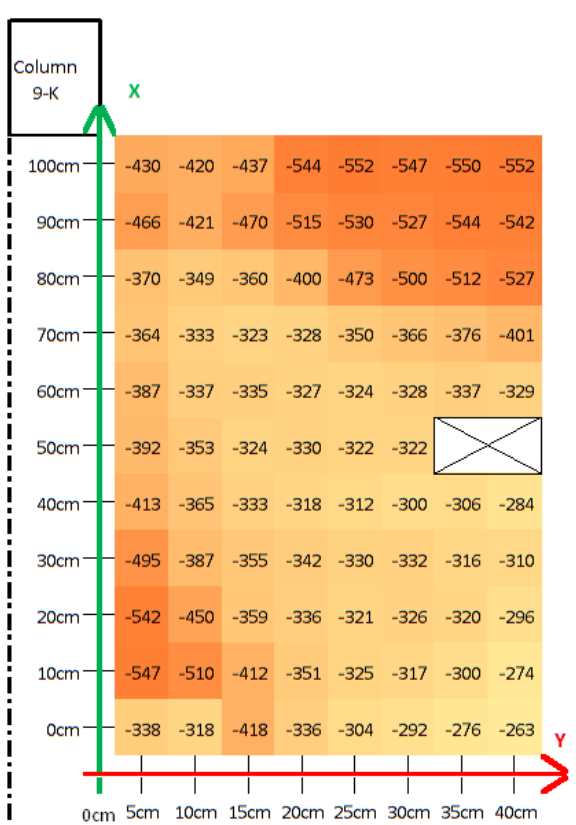


The potential mapping carried out confirms that the arrangement of the ZLA strips on the beam did not affect or protect the steel of the soffit surface.

Reinforcement in this zone would therefore be considered to be out of the influence of the cathodic protection system and therefore were not protected against corrosion.

These results do not allow validation of the ZLA disposition on the test beam, for the protection of the lateral parts adjacent to the slab intrados beams.

\subsection{Polarization results after adding ZLA on slab}

In order to obtain polarization effects for the slab soffit close to the beam, just a half layer $(12,5 \mathrm{~cm})$ of ZLA 450 $\mu \mathrm{m}$ was applied on the slab soffit as shown in Figure 11.
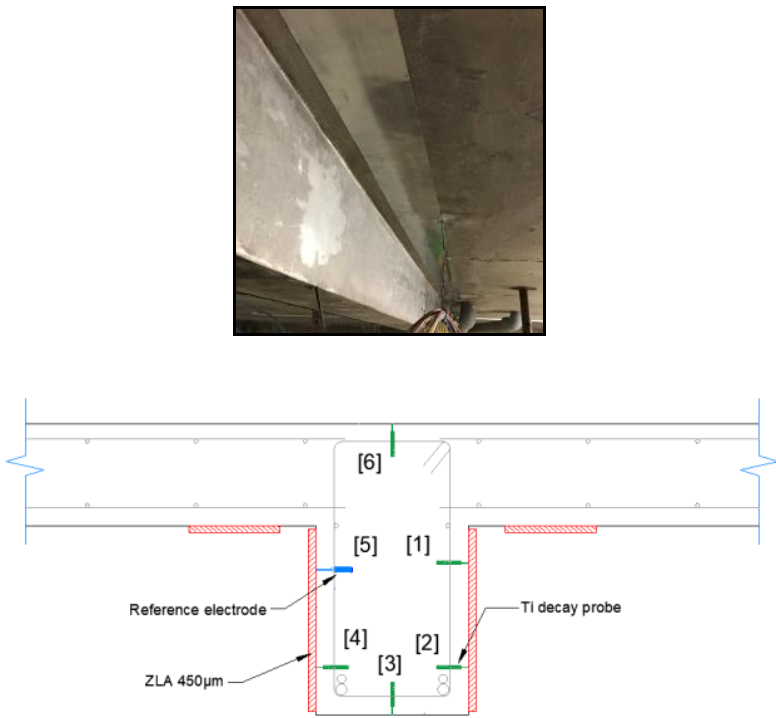

Fig. 11. ZLA layer on slab soffit

Table 4 shows the relative polarization effects based on the new anode configuration measured by the electrodes while the current has increased.

Table 4. Polarization results

\begin{tabular}{|c|c|c|}
\hline Measures & $\begin{array}{c}\mathbf{E}_{\text {ON 30/08/2018 }} \\
\text { 2ZLA strips }\end{array}$ & $\begin{array}{c}\mathbf{E}_{\text {ON30/08/2018 }} \\
\text { 2+ 2x1/2 ZLA strips }\end{array}$ \\
\hline $\begin{array}{c}\text { [1] - Dprobe } \\
(\mathrm{mV})\end{array}$ & -497 & -504 \\
\hline $\begin{array}{c}\text { [2] - Dprobe } \\
(\mathrm{mV})\end{array}$ & -552 & -551 \\
\hline $\begin{array}{c}\text { [3] - Dprobe } \\
(\mathrm{mV})\end{array}$ & -579 & -575 \\
\hline $\begin{array}{c}\text { [4] - Dprobe } \\
(\mathrm{mV})\end{array}$ & -526 & -531 \\
\hline $\begin{array}{c}\text { [5] - Ref } \\
(\mathrm{mV})\end{array}$ & -819 & -828 \\
\hline $\begin{array}{c}\text { [6] - Dprobe } \\
(\mathrm{mV})\end{array}$ & -192 & -210 \\
\hline $\begin{array}{c}\text { Current zone } \\
(\mathrm{mA})\end{array}$ & 84 & 141 \\
\hline
\end{tabular}

According to previous measurement on permanent reference electrode installed into the beam, surface potential measurements were carried out. Table 5 and 6 show the results of the On potentials mapped before and after the new configuration being installed
Table 5. Potential before installation

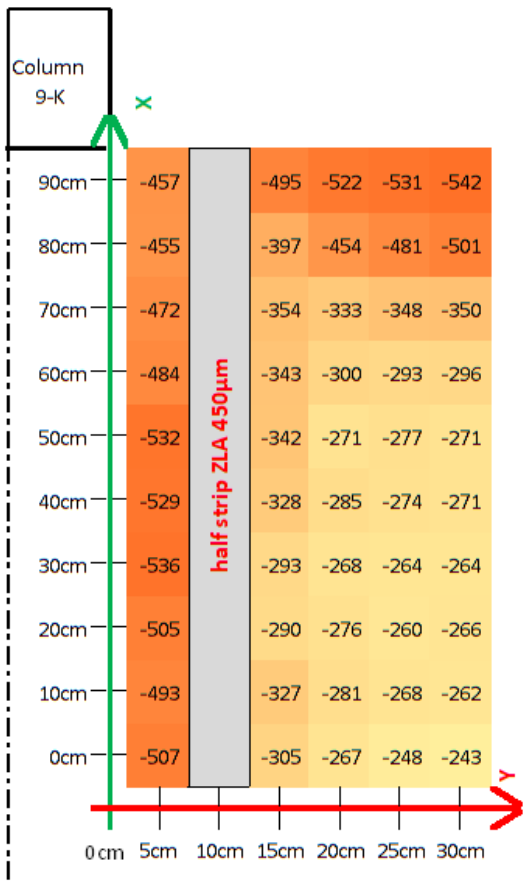

Table 6. Potential after installation

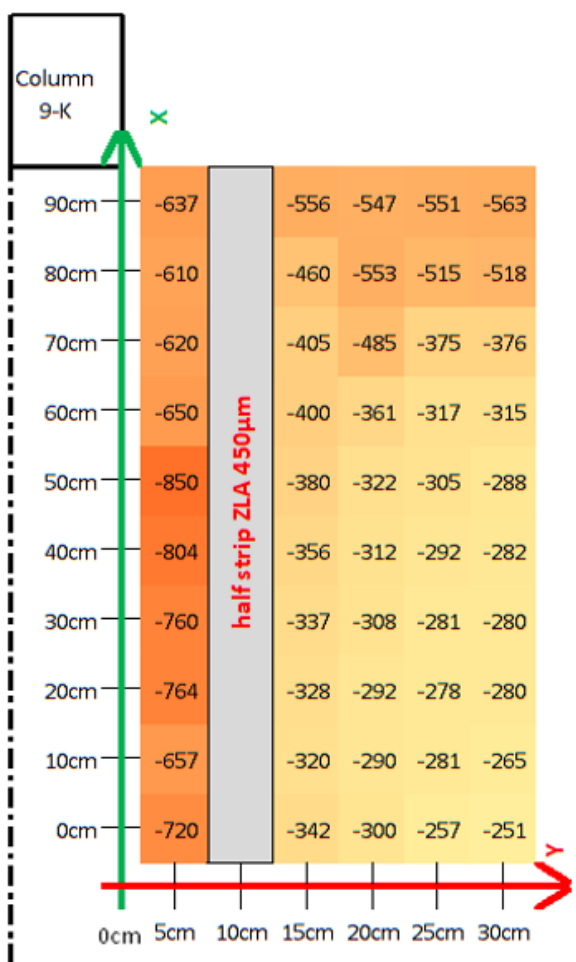

The potentials mapped confirm the positive effect of the additional ZLA strip being installed on the soffit, potentials adjacent to the new anode shifted more than $40 \mathrm{mV}$. 


\section{Results obtained for the cracked area}

\subsection{Polarization effect on slab}

The following Table 7 shows the results after 15 days polarization of the cracked soffit area.

Table 7. Potential after connection, soffit

\begin{tabular}{|c|c|c|c|c|c|c|}
\hline Measures & $\begin{array}{c}\mathbf{E}_{\text {native }} \\
18 / 06 / 2018\end{array}$ & $\begin{array}{c}\mathbf{E}_{\text {ON }} \\
18 / 06 / 2018\end{array}$ & $\begin{array}{c}\mathbf{E}_{\text {ON }} \\
02 / 07 / 2018\end{array}$ & $\begin{array}{c}\mathbf{E}_{\text {instant-off }} \\
02 / 07 / 2019\end{array}$ & $\begin{array}{c}\mathbf{E}_{\text {Off }+24 h} \\
03 / 07 / 2018\end{array}$ & $24 \mathrm{~h}$ Decay \\
\hline $\begin{array}{c}{[1]-\text { Dprobe }} \\
(\mathrm{mV})\end{array}$ & -222 & -487 & -444 & -432 & -208 & 223 \\
\hline $\begin{array}{c}{[2]-\text { Ref }} \\
(\mathrm{mV})\end{array}$ & -467 & -771 & -740 & -686 & -444 & 242 \\
\hline $\begin{array}{c}{[3]-\text { Dprobe }} \\
(\mathrm{mV})\end{array}$ & -232 & -586 & -557 & -492 & -220 & 272 \\
\hline $\begin{array}{c}\text { [4] - Dprobe } \\
(\mathrm{mV})\end{array}$ & -226 & -426 & -411 & -399 & -202 & 197 \\
\hline $\begin{array}{c}{[5]-\text { Dprobe }} \\
(\mathrm{mV})\end{array}$ & -210 & -388 & -372 & -365 & -198 & 167 \\
\hline $\begin{array}{c}{[6]-\text { Dprobe }} \\
(\mathrm{mV})\end{array}$ & -214 & -311 & -295 & -293 & -186 & 107 \\
\hline $\begin{array}{c}\text { Current zone } \\
(\mathrm{mA})\end{array}$ & 0 & 47 & 36 & 0 & 0 & \\
\hline
\end{tabular}

Depolarization readings show a significant effect for the soffit area, even at a $20 \mathrm{~cm}$ distance from the zinc strip (probe 5 and 6).

\subsection{Effect of the ZLA throwing power}

Tables 8 and 9 show the mapped potentials of the neighboring zones to the zinc strip.

The potential mapping details of the cracked area shown in Figure 12 are:

- Support: slab soffit adjacent to the ZLA

- Scope of mapping: $1.00 \mathrm{~m} \times 0.40 \mathrm{~m}$

- Grid of the mapping according to the direction of the ZLA: Axis-Y: $5 \mathrm{~cm}$, Axis-X: $10 \mathrm{~cm}, 86$ measures

- Electrode used: $\mathrm{Cu} / \mathrm{CuSO}_{4}$

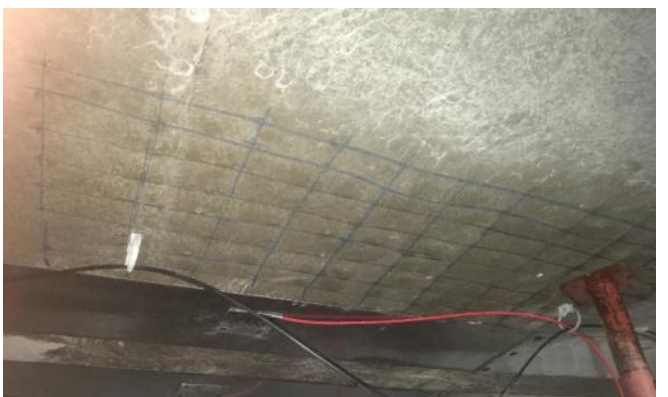

Fig. 12. Potential mapping area

The potentials mapped confirm the throwing power of the ZLA up to a distance of $20 \mathrm{~cm}$.

\section{Discussion}

Polarization readings showed the effective corrosion control of ZLA for the surface areas located on the beam and the adjacent surface area on the soffit.

Considering the current outputs and temperatures over four months' time during winter time, we clearly see a temperature dependence of the current output as shown in Figure 13, we can expect that during summer time this temperature effect on anodic current should be in the same range or greater.

Table 8. Potential mapping before connection

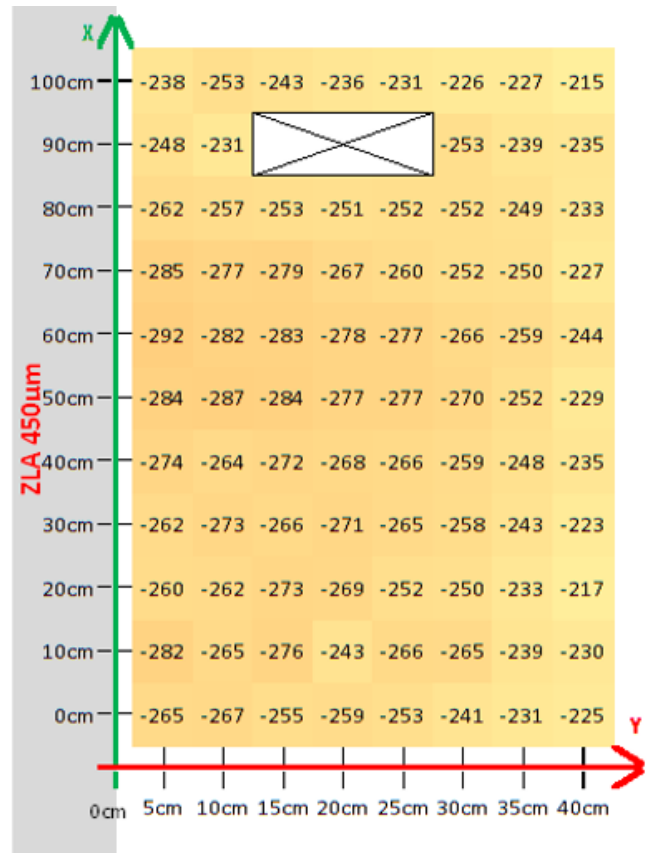

Table 9. Potential mapping after connection

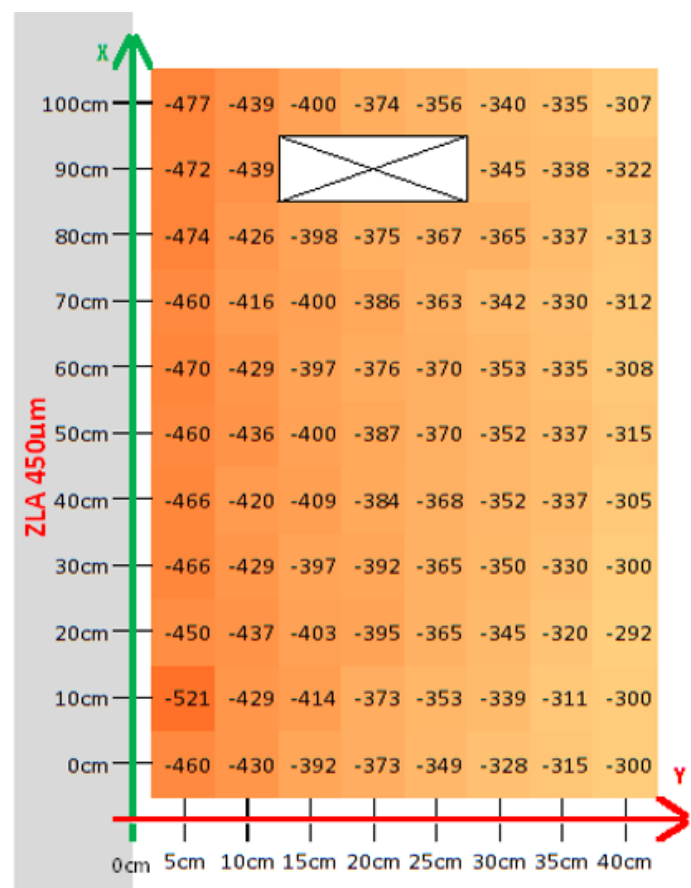

The current output for the beam and adjacent soffit area is $40 \mathrm{~mA}$ coming from $4.875 \mathrm{~m}^{2}$ ZLA surface area, which gives a current density of $8.2 \mathrm{~mA} / \mathrm{m}^{2} \mathrm{ZLA}$.

Considering the cracked soffit area, the readings gave a current output of $8 \mathrm{~mA}$ based on $1.95 \mathrm{~m}^{2} \mathrm{ZLA}$, which is $4.1 \mathrm{~mA} / \mathrm{m}^{2} \mathrm{ZLA}$.

This difference is due to the coupling ratio, in fact the steel rebar surface area is larger for the beam, $5.54 \mathrm{~m}^{2}$ than for the soffit surface area which is $2.3 \mathrm{~m}^{2}$. 
By calculating the zinc anode consumption rates with Faraday's law, one can estimate the service life of the system.

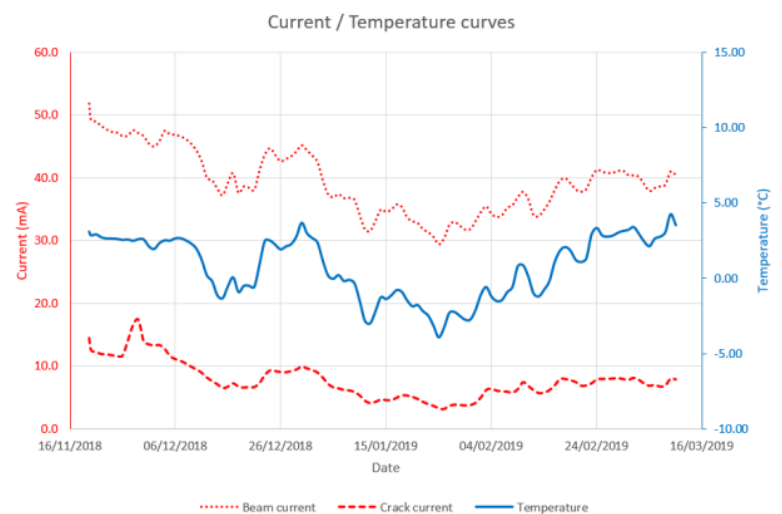

Fig. 13. Anodic current $(\mathrm{mA})$ versus temperature $\left({ }^{\circ} \mathrm{C}\right)$

The following table 10 shows the service life for both configurations according to an electrochemical capacity for the Zinc of $11.2 \mathrm{~kg} /$ A.year, efficiency of $90 \%$, utilisation factor of $80 \%$ and a Zinc weight of 3.15 $\mathrm{kg} / \mathrm{m}^{2}$, assuming constant current output.

Table 10. Life time expectation

\begin{tabular}{|c|c|c|}
\hline Configuration & $\begin{array}{c}\text { Anodic current density } \\
\mathbf{m A} / \mathbf{m}^{\mathbf{2}}\end{array}$ & $\begin{array}{c}\text { Life time } \\
\text { (years) }\end{array}$ \\
\hline Beam & 8,2 & 24,7 \\
\hline Soffit slab crack & 4,1 & 49,4 \\
\hline
\end{tabular}

The steel current density obtained after this trial phase was found to be in good agreement with polarization levels, respectively $7.22 \mathrm{~mA} / \mathrm{m}^{2}$ for the steel of the beam area and $3.47 \mathrm{~mA} / \mathrm{m}^{2}$ for the steel of the fractured slab area.

This current density matches well with the values given in the EN ISO 12696 for cathodic protection.

Over time, we obtained the confirmation that the system is working well, as the polarization readings indicate values exceed the $100 \mathrm{mV}$ criteria in the vicinity of the zinc layer anode.

\section{Conclusion}

Before implementing a cathodic protection on a job site, it is relevant to perform some tests on a 1:1 scale to take into account all the existing parameters.

Under these conditions, the ZLA solution has been confirmed to show test data suggesting an estimated service life of over 20 years.

\section{References}

1. R. J. Kessler, R. G. Powers, I. R. Lasa, Paper $\mathrm{N}^{\circ}$ 234, NACE Corrosion Conference (1997)

2. A.J. Van Den Hondel, J. Gulikers, R. Giorgini, A. Van Den Hondel, ICCRRR 2018, 199, 05004 (2018)
3. ISO EN 12696:2016, Cathodic Protection of Steel in Concrete 